\title{
BIPLOT UNTUK MENGETAHUI KARAKTERISTIK KABUPATEN/KOTA DI JAWA TENGAH BERDASARKAN PRODUKSI BAWANG PUTIH, BAWANG MERAH, CABE BESAR DAN CABE RAWIT
}

\author{
Diah Safitri $^{1}$, Suparti ${ }^{2}$, Esti Pratiwi ${ }^{3}$, Tyas Estiningrum ${ }^{4}$ \\ ${ }^{1,2}$ Dosen Jurusan Statistika FSM Undip \\ ${ }^{3,4}$ Mahasiswa Jurusan Statistika FSM Undip
}

\begin{abstract}
Abtract
Biplot is a graphical representation of a data matrix. Garlic, onions, chili, and thai pepper are important plant in Indonesia because most people in Indonesia especially in Central Java consume garlic, onions, chili, and thai pepper every day. In this research, districts in Central Java seen characteristics are based on the productions of garlic, onions, chili, and thai pepper using biplot. There are highly correlation between chili and thai pepper, which means districts that have highly productions of chili will also tend to have highly production of thai pepper. There are some districts have the production of garlic, onions, chili, and thai pepper relatively low, and there are some of the city has zero production of garlic, onions, chili, and thai pepper.
\end{abstract}

Keywords: Biplot, Production of garlic, onions, chili, thai pepper

\section{Pendahuluan}

Bawang putih merupakan salah satu komoditi pertanian yang banyak dibutuhkan penduduk di dunia, terutama dimanfaatkan sebagai bahan penambah penyedap atau pewangi beberapa jenis makanan. Umbi bawang putih mengandung sejenis minyak atsiri (methyl-allyl disulfida), dengan adanya kandungan minyak atsiri tersebut, bawang putih dapat digunakan sebagai bahan obat-obatan ${ }^{[6]}$ Beberapa ribu tahun yang lalu, bawang merah sudah dikenal dan digunakan orang, terutama untuk obat. Sampai kini pun bawang merah masih banyak digunakan untuk pengobatan dan juga sebagai bumbu penyedap masakan ${ }^{[7]}$. Cabe dikenal masyarakat sejak dahulu sebagai salah satu bumbu dapur utama. Rasanya yang pedas memang membuat masakan menjadi sedap dan meningkatkan selera makan ${ }^{[4]}$.

Biplot adalah representasi grafis dari informasi dalam matriks data $n x p$. Kata $b i$-mengacu pada dua jenis informasi yang terkandung dalam matriks data. Informasi dalam baris berkaitan dengan sampel atau unit pengambilan sampel dan dalam kolom berkaitan dengan variabel ${ }^{[2]}$. Biplot merupakan plot dari $\mathrm{n}$ pengamatan dan juga secara simultan plot dari posisi relatif $\mathrm{p}$ variabel dalam dua dimensi ${ }^{[3]}$.Analisis biplot dapat digunakan untuk mengetahui mana variabel yang mempunyai nilai yang tinggi dan biplot dapat juga digunakan untuk memperoleh informasi variabel mana yang berkorelasi tinggi, variabel mana yang tidak berkorelasi, dan variabel mana yang berkorelasi negatif ${ }^{[5]}$.

Dalam penelitian ini, Kabupaten/kota di Jawa Tengah akan dilihat karakteristiknya berdasarkan produksi bawang merah, bawang putih, cabe besar dan cabe rawit menggunakan analisis biplot. Dengan menggunakan biplot akan dilihat mana yang mempunyai korelasi tinggi antara produksi bawang putih, bawang merah, cabe besar, cabe rawit dan kabupaten/kota mana yang menonjol pada produksi bawang putih, bawang merah, cabe besar dan cabe rawit. 


\section{Tinjauan Pustaka}

Biplot adalah representasi dua dimensi dari suatu matriks data yang menampilkan suatu titik untuk setiap $\mathrm{n}$ vektor amatan (baris dari matriks data) seiring dengan suatu titik untuk setiap p variabel (kolom dari matriks data) ${ }^{[5]}$. Konstruksi biplot berasal dari komponen utama sampel . Suatu plot dua dimensi dari unit sampling dapat diperoleh dengan membuat grafik dari dua komponen utama pertama ${ }^{[2]}$.

Komponen utama diberikan oleh $\mathrm{z}=\mathbf{a}^{\prime} \mathbf{y}$, dengan a adalah vektor eigen dari matriks kovarians sampel, dan $\mathbf{y}$ adalah vektor amatan berukuran $\mathrm{p} \times 1$. Terdapat $\mathrm{p}$ vektor eigen (yaitu $\left.\mathbf{a}_{1}, \mathbf{a}_{2}, \ldots, \mathbf{a}_{\mathrm{p}}\right)$ dan $\mathrm{p}$ komponen utama $\left(\mathrm{z}_{1}, \mathrm{z}_{2}, \ldots, \mathrm{z}_{\mathrm{p}}\right)$ untuk setiap vektor amatan $\mathbf{y}_{\mathrm{i}}$ dengan $\mathrm{i}=1,2, \ldots, \mathrm{n}$. Vektor amatan $\mathbf{y}_{\mathrm{i}}$ ditransformasi menjadi :

$$
\mathrm{z}_{\mathrm{ij}}=\mathbf{a}_{\mathrm{j}}^{\prime}\left(\mathbf{y}_{\mathrm{i}}-\overline{\mathbf{y}}\right)=\left(\mathbf{y}_{\mathrm{i}}-\overline{\mathbf{y}}\right)^{\prime} \mathbf{a}_{\mathrm{j}}, \mathrm{i}=1,2, \ldots, \mathrm{n} \text { dan } \mathrm{j}=1,2, \ldots, \mathrm{p}
$$

Setiap vektor amatan $\mathbf{y}_{\mathrm{i}}$ (berukuran $\mathrm{p}$ x 1) ditransformasi menjadi vektor komponen utama berukuran $\mathrm{p}$ x 1 :

$$
\begin{aligned}
& z_{i}^{\prime}=\left[\left(y_{i}-\bar{y}\right)^{\prime} a_{1},\left(y_{i}-\bar{y}\right)^{\prime} a_{2}, \ldots,\left(y_{i}-\bar{y}\right)^{\prime} a_{p}\right] \\
& =\left(y_{i}-\bar{y}\right)^{\prime}\left(a_{1}, a_{2}, \ldots, a_{p}\right) \\
& =\left(\mathrm{y}_{\mathrm{i}}-\overline{\mathrm{y}}\right)^{\prime} \mathrm{A} \\
& \text { untuk } \mathrm{i}=1,2, \ldots, \mathrm{n} \\
& \text { dengan } \mathbf{A}=\left(\mathbf{a}_{1}, \mathbf{a}_{2}, \ldots, \mathbf{a}_{\mathrm{p}}\right)
\end{aligned}
$$

Komponen utama dapat dituliskan dalam bentuk $\mathbf{Z}=\mathbf{Y}_{\mathrm{c}} \mathbf{A}$, dengan :

$$
\begin{aligned}
& \mathbf{Z}=\left(\begin{array}{l}
\mathbf{z}_{1}^{\prime} \\
\mathbf{z}_{2}^{\prime} \\
\vdots \\
\mathbf{z}_{\mathrm{n}}^{\prime}
\end{array}\right) \\
& \mathbf{Y}_{\mathrm{c}}=\left(\begin{array}{l}
\left(\mathbf{y}_{1}-\overline{\mathbf{y}}\right)^{\prime} \\
\left(\mathbf{y}_{2}-\overline{\mathbf{y}}\right)^{\prime} \\
\vdots \\
\left(\mathbf{y}_{\mathrm{n}}-\overline{\mathbf{y}}\right)^{\prime}
\end{array}\right)
\end{aligned}
$$

Dari $\mathbf{Z}=\mathbf{Y}_{\mathrm{c}} \mathbf{A}$, dapat dituliskan $\mathbf{Z} \mathbf{A}^{\prime}=\mathbf{Y}_{\mathrm{c}} \mathbf{A} \mathbf{A}^{\prime}$, karena $\mathbf{A} \mathbf{A}^{\prime}=\mathbf{I}$, diperoleh:

$$
\mathbf{Y}_{\mathrm{c}}=\mathbf{Z A}^{\prime}
$$

Representasi dua dimensi dari $\mathbf{Y}_{\mathrm{c}}$ mengambil dua kolom pertama dari matriks $\mathbf{Z}$ dan dinotasikan dengan $\mathbf{Z}_{2}$, serta dua kolom pertama dari matriks $\mathbf{A}$ dan dinotasikan dengan $\mathbf{A}_{2}$ :

$$
\mathbf{Y}_{\mathrm{c}} \cong \mathbf{Z}_{2} \mathbf{A}_{2}^{\prime}
$$

Koordinat pada biplot untuk $\mathrm{n}$ amatan adalah baris dari $\mathbf{Z}_{2}$ dan koordinat untuk $\mathrm{p}$ variabel adalah baris dari $\mathbf{A}_{2}{ }^{[5]}$.

Komponen utama selain dapat dibentuk dari vektor eigen matriks kovarians, juga dapat dibentuk dari vektor eigen matriks korelasi ${ }^{[2]}$.

Posisi- posisi dari variabel dalam plot ditunjukkan oleh suatu vektor. Unit yang dekat dengan suatu variabel mempunyai nilai yang tinggi pada variabel tersebut ${ }^{[2]}$. Sudut yang kecil antara dua vektor menunjukkan bahwa dua variabel berkorelasi tinggi, dua variabel yang vektornya membentuk sudut $90^{\circ}$ adalah tidak berkorelasi, dan suatu sudut yang lebih besar dari $90^{\circ}$ menunjukkan bahwa variabel tersebut berkorelasi negatif ${ }^{[5]}$. 


\section{Metode Penelitian}

Data yang digunakan dalam penelitian ini adalah data produksi bawang putih, bawang merah, cabe besar, dan cabe rawit di Kabupaten/Kota di Jawa Tengah tahun 2011 yang diambil dari situs resmi Badan Pusat Statistik Jawa Tengah, kemudian biplot dibuat dengan bantuan software Minitab, selanjutnya biplot yang sudah diperoleh dianalisa untuk mengetahui karakteristik Kabupaten/Kota di Jawa Tengah berdasarkan produksi bawang putih, bawang merah, cabe besar, dan cabe rawit.

Langkah-langkah analisis pada penelitian ini:

a. Menyiapkan data produksi bawang putih, bawang merah, cabe besar, dan cabe rawit di Kabupaten/Kota di Jawa Tengah tahun 2011 yang diambil dari situs resmi Badan Pusat Statistik Jawa Tengah

b. Data produksi bawang putih, bawang merah, cabe besar, dan cabe rawit di Kabupaten/Kota di Jawa Tengah tahun 2011 disusun dalam bentuk matriks Y yang berukuran $\mathrm{n} x \mathrm{p}$

c. Membuat komponen utama untuk matriks $\mathbf{Y}$

d. Membuat matriks $\mathbf{Z}$ dan matriks $\mathbf{A}$

e. Membuat matriks $\mathbf{Z}_{2}$ yang mengambil dua kolom pertama dari matriks $\mathbf{Z}$

f. Membuat matriks $\mathbf{A}_{2}$ yang mengambil dua kolom pertama dari matriks $\mathbf{A}$

g. Membuat biplot (baris dari $\mathbf{Z}_{\mathbf{2}}$ sebagai koordinat untuk $\mathrm{n}$ amatan dan baris dari $\mathbf{A}_{\mathbf{2}}$ sebagai koordinat untuk $\mathrm{p}$ variabel)

h. Melakukan analisa pada biplot.

Diagram alir analisis data:

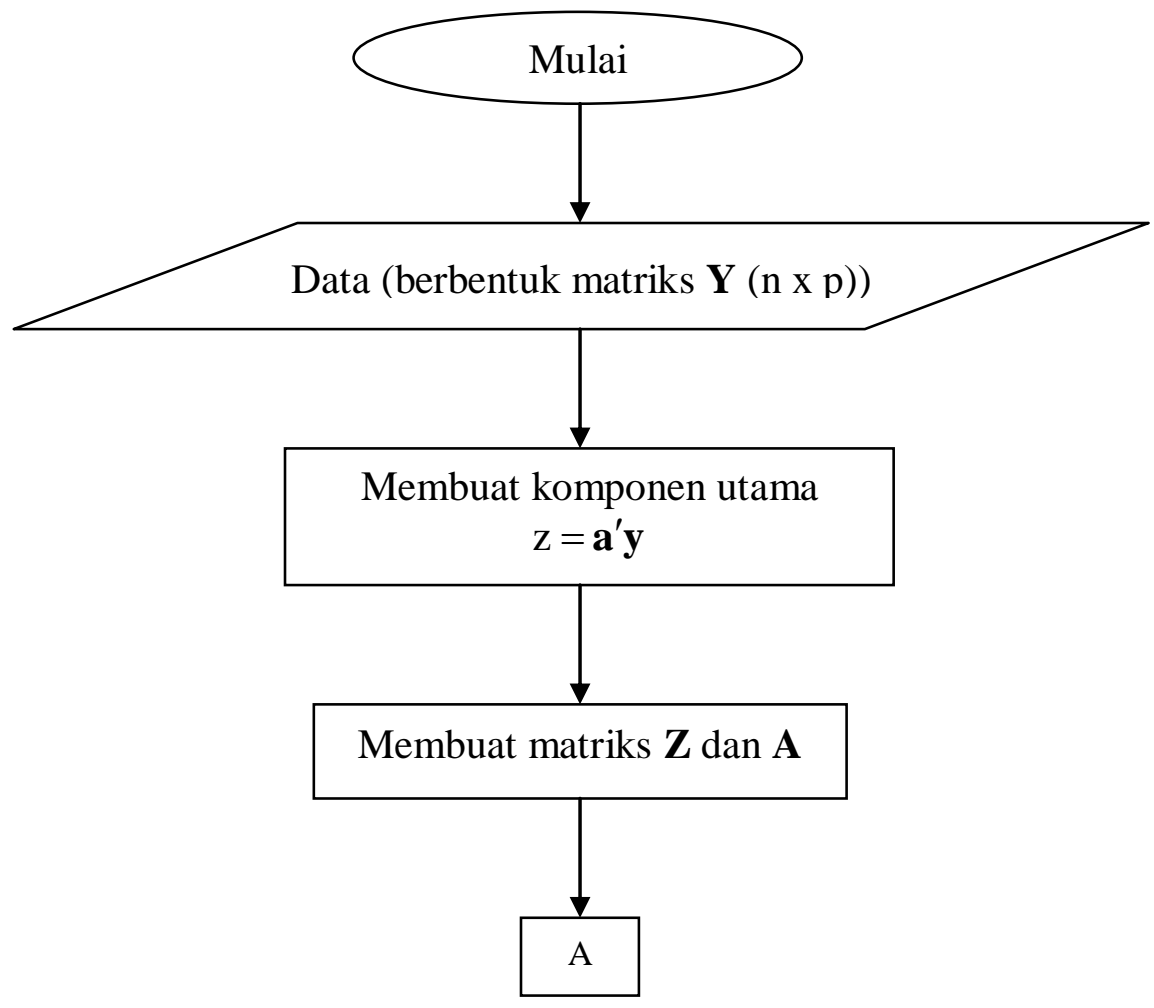




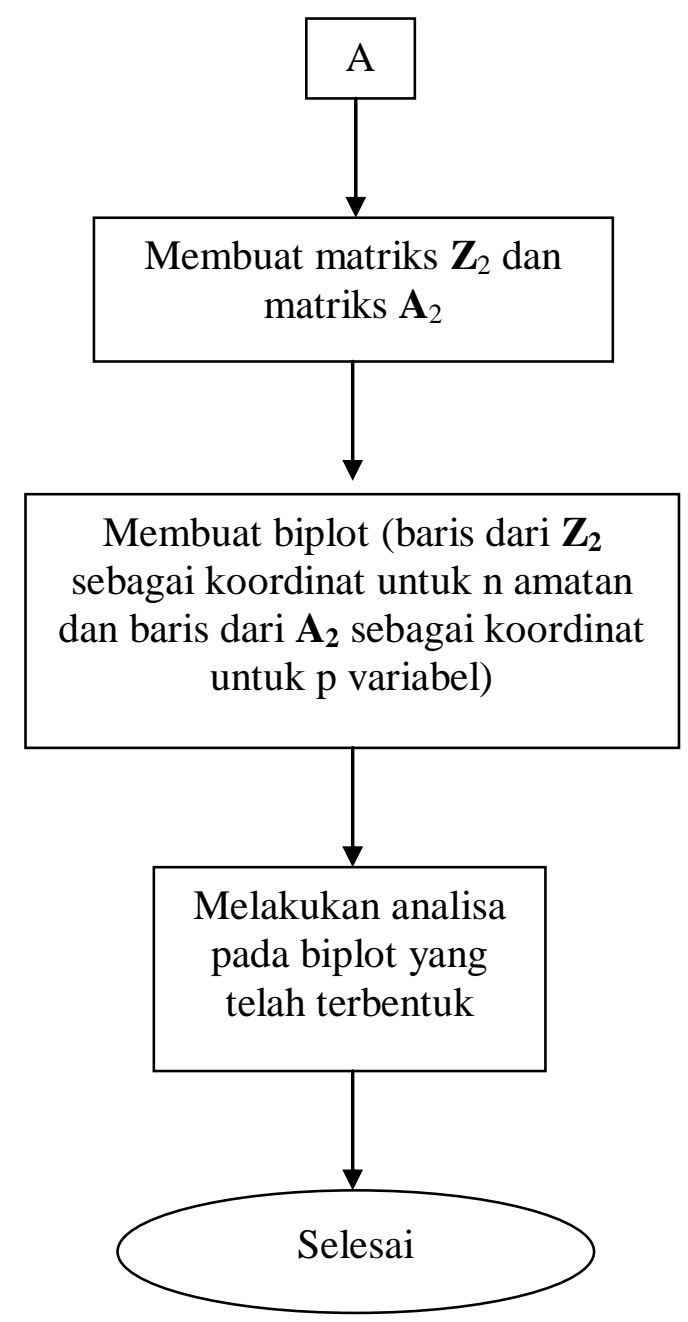

Gambar 1. Diagram Alir Analisis Data

\section{Hasil dan Pembahasan}

Data produksi bawang putih, bawang merah, cabe besar, dan cabe rawit di Kabupaten/Kota di Jawa Tengah tahun 2011 yang diambil dari situs resmi Badan Pusat Statistik Jawa Tengah, dibuat biplot dengan bantuan software Minitab, diperoleh output berupa biplot yang dapat dilihat pada Gambar 2 .

Terdapat korelasi tinggi antara produksi cabe besar dan cabe rawit, antara produksi bawang merah dan cabe rawit dan juga antara produksi bawang merah dan cabe besar karena dapat dilihat pada Gambar 2 bahwa terdapat sudut yang kecil antara 2 vektor, dan yang mempunyai korelasi paling tinggi adalah antara produksi cabe besar dan cabe rawit. Oleh karena itu kabupaten/kota yang mempunyai angka tinggi pada produksi cabe besar akan mempunyai angka tinggi pada produksi cabe rawit, kabupaten/kota yang mempunyai angka tinggi pada produksi bawang merah akan mempunyai angka tinggi pada produksi cabe rawit, kabupaten/kota yang mempunyai angka tinggi pada produksi bawang merah akan mempunyai angka tinggi pada produksi cabe besar.

Pada Gambar 2 dapat dilihat bahwa Kabupaten Karanganyar menonjol pada produksi bawang putih, Kabupaten Brebes mempunyai angka produksi bawang merah yang tinggi, Kabupaten Magelang menonjol pada produksi cabe besar, dan Kabupaten Boyolali menonjol pada produksi cabe rawit. 


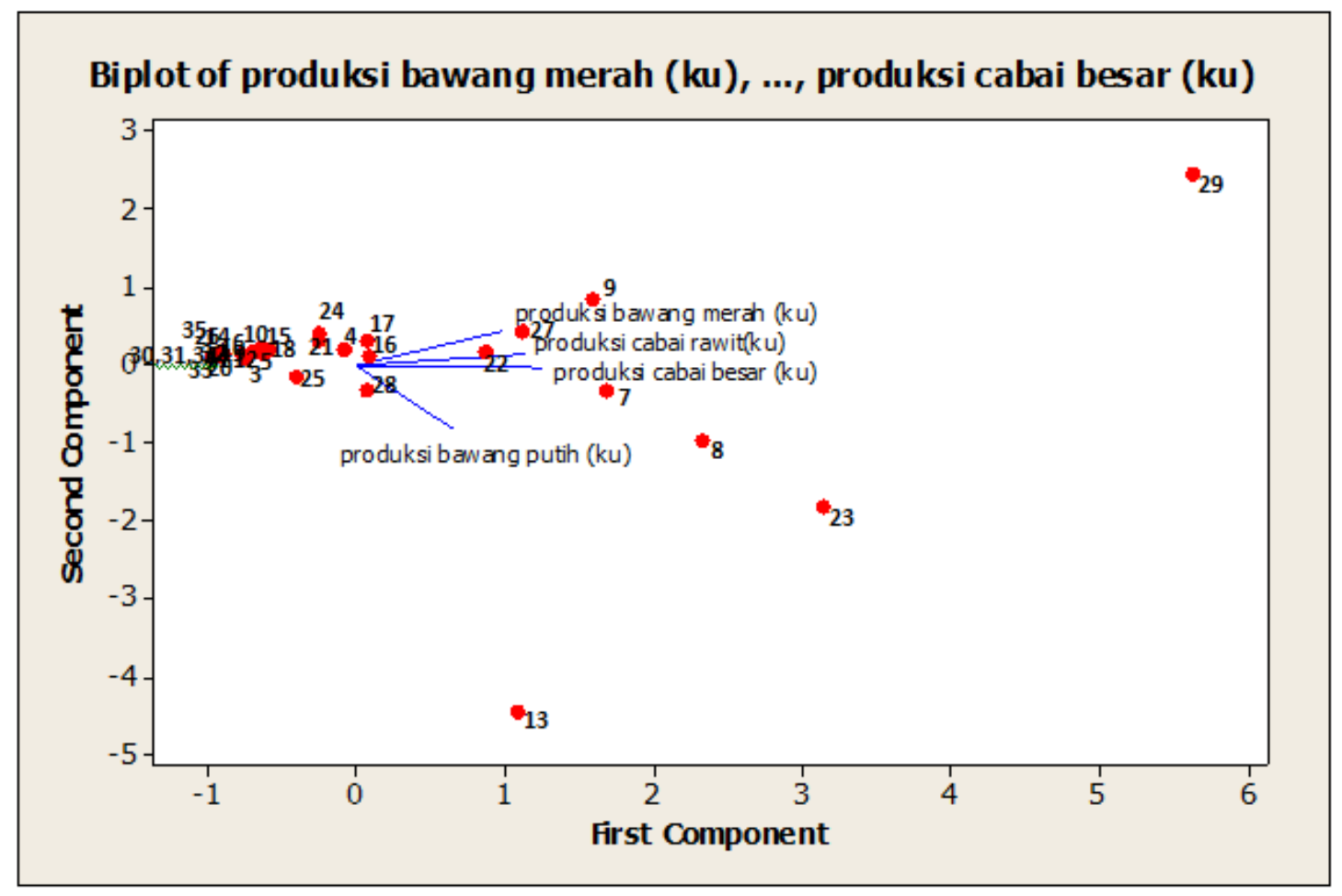

Gambar 2. Biplot dari data produksi bawang putih, bawang merah, cabe besar, dan cabe rawit Kabupaten/Kota di Jawa Tengah tahun 2011

Kabupaten Cilacap, Kabupaten Banyumas, Kabupaten Purbalingga, Kabupaten Kebumen, Kabupaten Purworejo, Kabupaten Klaten, Kabupaten Sukoharjo, Kabupaten Wonogiri, Kabupaten Sragen, Kabupaten Grobogan, Kabupaten Pati, Kabupaten Kudus, Kabupaten Pekalongan, Kota Magelang, Kota Surakarta, Kota Salatiga, Kota Semarang, Kota Pekalongan, dan Kota Tegal merupakan kabupaten/kota dengan karakteristik mirip dalam hal produksi bawang putih, bawang merah, cabe besar, cabe rawit yaitu angka produksi bawang putih, bawang merah, cabe besar, cabe rawit relatif rendah. Berdasarkan data produksi bawang putih, bawang merah, cabe besar, dan cabe rawit di Kabupaten/Kota di Jawa Tengah tahun 2011, ada beberapa kota di Jawa Tengah yang memang mempunyai angka produksi nol pada produksi bawang putih, bawang merah, cabe besar, dan cabe rawit yaitu Kota Magelang, Kota Surakarta, Kota Pekalongan.

\section{Kesimpulan dan Saran}

Terdapat korelasi positif yang tinggi antara cabe besar dan cabe rawit, yang berarti kabupaten/kota yang mempunyai angka tinggi pada produksi cabe besar akan cenderung mempunyai angka yang tinggi juga pada produksi cabe rawit

Ada beberapa kabupaten/kota yang mempunyai angka produksi bawang putih, bawang merah, cabe besar, cabe rawit relatif rendah. Ada beberapa kota yang mempunyai angka produksi nol pada produksi bawang putih, bawang merah, cabe besar, dan cabe rawit. Untuk kabupaten/kota yang mempunyai iklim dan kondisi suhu, tanah, dan ketinggian tempat yang cocok untuk bertanam bawang putih, bawang merah, cabe besar, atau cabe rawit, sebaiknya diusahakan secara maksimal agar kabupaten/kota tersebut dapat menghasilkan bawang putih, bawang merah, cabe besar, atau cabe rawit dengan angka produksi yang tinggi. 


\section{DAFTAR PUSTAKA}

1. Badan Pusat Statistika, Jawa Tengah Dalam Angka 2012, URL: http://jateng.bps.go.id/

2. Johnson, R. A. \& Wichern, D. W, Applied Multivariate Statistical Analysis, Sixth Edition, Pearson Prentice Hall, 2007.

3. Jollife, I. T., Principal Component Analysis, Second Edition, Springer-Velag New York Inc., New York, 2002.

4. Redaksi AgroMedia, Petunjuk Praktis Bertanam Cabai, PT AgroMedia Pustaka, Jakarta, 2011.

5. Rencher, A. C., Methods of Multivariate Analysis, Second Edition, John Wiley \& Sons, Inc , 2002.

6. Santoso, H. B., Bawang Putih, Kanisius, Yogyakarta, 1992.

7. Wibowo, S., Budi Daya Bawang, Penebar Swadaya, Jakarta, 2009. 